\section{Regards sur l'économie allemande}

Bulletin économique du CIRAC

$81 \mid 2007$

Varia

\title{
Assurance sociale : la croissance renfloue les caisses
}

Isabelle Bourgeois

\section{(2) OpenEdition}

1 Journals

Édition électronique

URL : http://journals.openedition.org/rea/677

DOI : $10.4000 /$ rea. 677

ISBN : 978-2-8218-0858-4

ISSN : 1965-0787

\section{Éditeur}

CIRAC

Édition imprimée

Date de publication : 1 mai 2007

Pagination : 38

ISSN : 1156-8992

\section{Référence électronique}

Isabelle Bourgeois, "Assurance sociale : la croissance renfloue les caisses ", Regards sur l'économie allemande [En ligne], 81 | mai 2007, document 4, mis en ligne le 01 mai 2009, consulté le 15 septembre 2020. URL : http://journals.openedition.org/rea/677

Ce document a été généré automatiquement le 15 septembre 2020

(C) CIRAC 


\title{
Assurance sociale : la croissance renfloue les caisses
}

\author{
Isabelle Bourgeois
}

1 La croissance ne bénéficie pas qu'aux budgets des collectivités territoriales qui voient affluer les recettes fiscales. Elle est aussi à l'origine de l'excédent (20,5 milliards $€$ ) enregistré en 2006 par les caisses publiques d'assurance sociale, après une année 2005 déficitaire (-3,3 milliards $€$ ), annonce Destatis. L'excédent s'explique par une hausse des recettes, due à l'embellie conjoncturelle. Les problèmes de fond demeurent.

2 Reflet de la baisse du chômage liée à la croissance et aux réformes Hartz, l'Agence fédérale pour l'emploi a vu s'accroître ses recettes de $+6,6$ \% (total : 56,6 milliards $€$ ) pendant que ses dépenses baissaient de -14,6 \% (total : 45,4 milliards $€$ ). Mais l'excédent est exceptionnel. Dès 2007, l'abaissement du taux de cotisation chômage (de 6,5 à 4,2 \% du salaire brut) se soldera par une réduction annuelle de 17 milliards $€$ de ses recettes.

3 L'excédent des caisses légales de retraite s'est élevé à 7,3 milliards $€$ (total recettes : 240,2 milliards $€$ ) après un déficit de 4,3 milliards $€$ en 2005. Cette situation exceptionnelle s'explique principalement par la modification de la période de perception des cotisations, passées de la fin au début du mois en janvier/février 2006. Le problème du financement des dépenses demeure: elles restent en hausse et connaitront une explosion avec l'entrée massive prochaine à la retraite des babyboomers. Il n'est pas exclu alors que les cotisations devront être relevées de 19,9 à $22 \%$. La réforme qui porte à 67 ans l'âge légal de départ à la retraite ne prendra pleinement effet qu'à partir de 2030.

4 L'excédent des caisses légales d'assurance maladie s'est élevé à 1,7 milliard $€$ (après 1,5 milliard $€$ ). Leur situation reste tendue étant donné qu'elles ont puisé depuis des années dans leurs réserves pour équilibrer leurs comptes et que, dans le cadre de sa politique de réduction du déficit, le gouvernement fédéral abaisse le montant du complément fiscal qu'il leur verse (passé de 4,2 à 2,5 milliards $€$ entre 2006 et 2007). La hausse de 0,6 point des cotisations au $1^{\mathrm{er}}$ janvier 2007 (taux moyen actuel : 14,82\%) ne suffira pas à compenser la hausse incompressible des dépenses. Le Fonds Santé qui sera créé en 2009 ne résout pas le problème de leur financement. 
5 Une réforme s'impose d'urgence aussi dans le domaine de l'assurance dépendance légale. L'excédent de 500 millions $€$ (total dépenses : 18 milliards $€$ ) enregistré en 2006 est lui aussi exceptionnel (les retraités sont désormais soumis à cotisations) et masque un sous-financement chronique des dépenses. Le catalogue des prestations a certes été réduit depuis 1995; mais du fait du vieillissement démographique, le nombre des personnes dépendantes ne cesse de croître.

INDEX

Mots-clés : assurance maladie, croissance, santé 